\title{
MEASURING THE GENEROSITY OF UNEMPLOYMENT BENEFIT SYSTEMS: EVIDENCE FROM HUNGARY AND ELSEWHERE IN CENTRAL EUROPE
}

\author{
E. BARDASI, A. LASAOSA, J. MICKLEWRIGHT and GY. NAGY \\ (Received: 12 September 2000; revision received: 15 November 2000; \\ accepted: 21 November 2000)
}

\begin{abstract}
The paper considers two aspects of the targeting of unemployment benefit systems: (a) the probability that benefit is received in the population of those unemployed on standard international criteria of search and availability, and (b) the probability in the population of benefit recipients that search is conducted. The focus is on Hungary but stylised facts for a range of Central European countries and two EU comparators are derived in the first part of the paper. The second part of the paper finds that most of the large decline in coverage of the Hungarian unemployed by insurance benefit (received by only a quarter of the searching stock in 1997) cannot be explained by changes in the composition of unemployment observable in labour force survey data (including unemployment duration). The probability of active search (search other than through a state employment office) is found to be very similar for those receiving insurance and assistance benefit.
\end{abstract}

Keywords: unemployment benefit, search

JEL classification index: J64, J65

\section{INTRODUCTION}

Descriptions of the generosity of unemployment benefit schemes typically rely on two methods of presentation. The first, often found in cross-national comparisons of benefit systems (e.g. Burda, 1993; OECD, 1994), concentrates on the benefit entitlement of hypothetical persons, for example someone who previously earned the average industrial wage and who has a good employment history. Calculations are made for different durations of unemployment and for persons with different family circumstances, for example a married man with dependent wife and two dependent children. For obvious reasons, this is an unsatisfactory method of pre-

Corresponding author: J. Micklewright, UNICEF Innocenti Research Centre, Piazza SS Annunziata, 12.50122 Florence, Italy. E-mail: jmicklewright@unicef.org 
sentation since the assumed characteristics cannot be representative of the wide range of types of persons who actually experience unemployment. Moreover, benefit systems often have rules that defy easy summary through stylised calculations.

The second method focuses on benefit coverage, presenting proportions of the registered unemployed receiving benefits of different types, whether across countries or across time. Administrative sources accurately record how many persons do actually receive benefit of different types, but are likely to give biased estimates of benefit coverage of the genuinely unemployed - biases that will vary over time and across country and between different sub-groups in the unemployed population. Many persons who are unemployed may not register as such, precisely on account of their lack of eligibility for unemployment benefits. And, on the other hand, administrative data will contain persons receiving benefits who are not genuinely unemployed.

This paper focuses on measurement of two basic aspects of benefit coverage that represent sides of the same coin: (a) the proportion of all persons defined as unemployed on the standard ILO/OECD criteria of search and availability who do in fact receive unemployment benefit, and (b) the proportion of all persons who receive benefits who do in fact conduct search. Although coverage is not usually analysed in this way, these are two of the natural yardsticks for assessing the success of income support policy. Do the ILO/OECD unemployed (who are looking for a job and are available to start work) receive help from the state? And do those receiving help from the state conduct job search? The recent renaming in the UK of unemployment benefit as "Job Seekers' Allowance" emphasises this way of looking at benefit systems - benefit is intended for those who search (although it is clear that search is seen as a necessary and not a sufficient condition). One might characterize a well-targeted unemployment benefit system as being generous in coverage towards searchers but restrictive in coverage of those not searching. The labour force survey data we use in this paper allow analysis of both these aspects of benefit generosity.

In the first part of the paper we derive some stylised facts about benefit targeting, in the sense just given, in five Central European countries - the Czech Republic, Hungary, Poland, Slovakia and Slovenia - and two Western European countries - Spain and the UK. There has been a lively debate on the issues surrounding unemployment benefit in Central Europe during transition (e.g. OECD, 1996), but no analysis that we are aware of has considered the overlap between the populations of benefit recipients and searchers in different countries. Spain and the UK are countries where the association between benefit and search has seen much more analysis (although not in the way we approach the issues) and they present two differing comparators for the Central European group. The results show that 
less than half of the unemployed in Slovenia, Poland, and the Czech Republic received any form of unemployment benefit in 1994-95, a characteristic shared by Spain, but that among this group only in Slovenia did less than half of those with benefit report search. In all the countries analysed, benefit is less well-targeted on women: fewer searchers receive benefit than men and fewer women with benefit undertake search, although the gender differences are notably smaller in the Central European countries than in the two Western comparators.

In the second part of the paper we investigate why targeting of benefit has clearly worsened over the 1990s in one of the Central European countries, Hungary. Both the proportion of ILO/OECD unemployed with unemployment benefit and the proportion of those with benefit who searched fell in Hungary by some 15 percent points over 1993-97. In particular, the coverage of unemployment insurance secured by prior contributions fell enormously and now provides support to only a quarter of the unemployed seeking work. To what extent was this due to change in the composition of the unemployed, as opposed to cuts in the generosity of insurance benefit? We find that the rise in long-term unemployment and the changing composition of the unemployed in terms of other observable characteristics as age and education explain do not explain most of the fall in benefit coverage, which must therefore reflect a combination of the impact of policy changes and worsening work histories. We find no evidence that the frequency of active search differs between those receiving insurance benefit and those receiving the means-tested assistance benefit that has grown in importance, a result that calls into question the view that those on assistance benefit are less attached to the labour force.

\section{CROSS-NATIONAL COMPARISONS OF BENEFIT COVERAGE: CENTRAL EUROPE}

To compare coverage of unemployment benefit systems across countries we draw on the labour force survey microdata in the Luxembourg Employment Study (LES). This is the recently developed twin sister of the well-known Luxembourg Income Study (LIS) that brings together and harmonizes income surveys from a range of countries. The surveys in the LIS are often of a very different nature, while the LES has the advantage that its constituent labour force surveys are more inherently comparable, with common definitions of some important concepts. These include the definition of unemployment, which follows the ILO/OECD definition of search and availability. Hence using the LES we are able to see how two key aspects of benefit targeting - coverage of searchers and search by recipients - varies across a group of countries. Our principal interest is in the five Cen- 
tral European countries that were included in the LES from its conception, but we also take the UK and Spain as Western European comparators.

As with all cross-country comparisons, results may be sensitive to the year taken for analysis and this is a particular concern in the study of transition economies where labour market developments and policy changes may quickly lead to changes in the picture obtained. However, in contrast to the LIS, the LES does not currently provide any choice of year for analysis. (The second half of the paper shows the changing picture for Hungary with data obtained directly from the Hungarian Central Statistical Office.) The Central European data in the LES relate to 1993 for Hungary and 1994 for the Czech Republic, Poland, Slovakia, and 1995 for Slovenia. The UK data refer to 1989 and those for Spain to 1993. Figure 1 shows the unemployment rates in these years for the quarter for which survey data are included in the LES, distinguishing between the measure using the ILO/OECD definition taken from the survey data and that based on the official unemployment register.

At just under 4 percent, the Czech Republic has much the lowest unemployment rate in the Central European group, less than half that in the country with the next lowest rate, Slovenia. Rates in Hungary, Poland and Slovakia are all around 13-14 percent. The two EU comparators have rates that differ sharply, with the UK coming between the Czech Republic and Slovenia while Spain far outstrips all

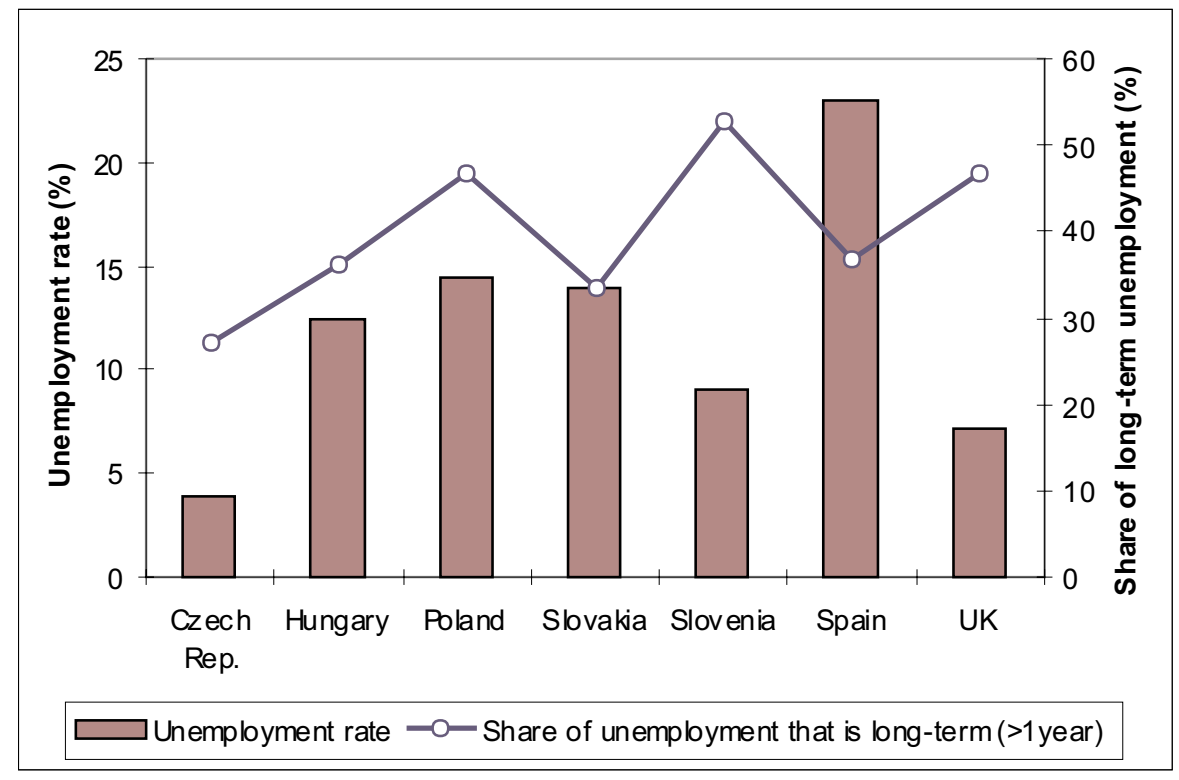

Figure 1. ILO/OECD unemployment rate and share of long-term unemployment 
the Central European group with over a fifth of the workforce unemployed. To what extent are these differences in unemployment rates associated with a very different proportion of long-term unemployment - those who have searched for more than a year? The long-term unemployed are less likely to receive insurance benefit limited by duration of receipt, and variations in the degree of long-term unemployment may be one important cause of differences in benefit coverage. Figure 1 shows that while the Czech Republic in 1994 had a notably low share of long-term unemployment to go with its markedly low unemployment rate, in general there is no simple association between the two measures, as the comparison of Slovenia and Spain or Hungary and Slovakia highlights. ${ }^{1}$

Figure 2 shows the basic picture of benefit coverage in the labour force surveys contained in the LES data. The vertical axis shows the proportion of the

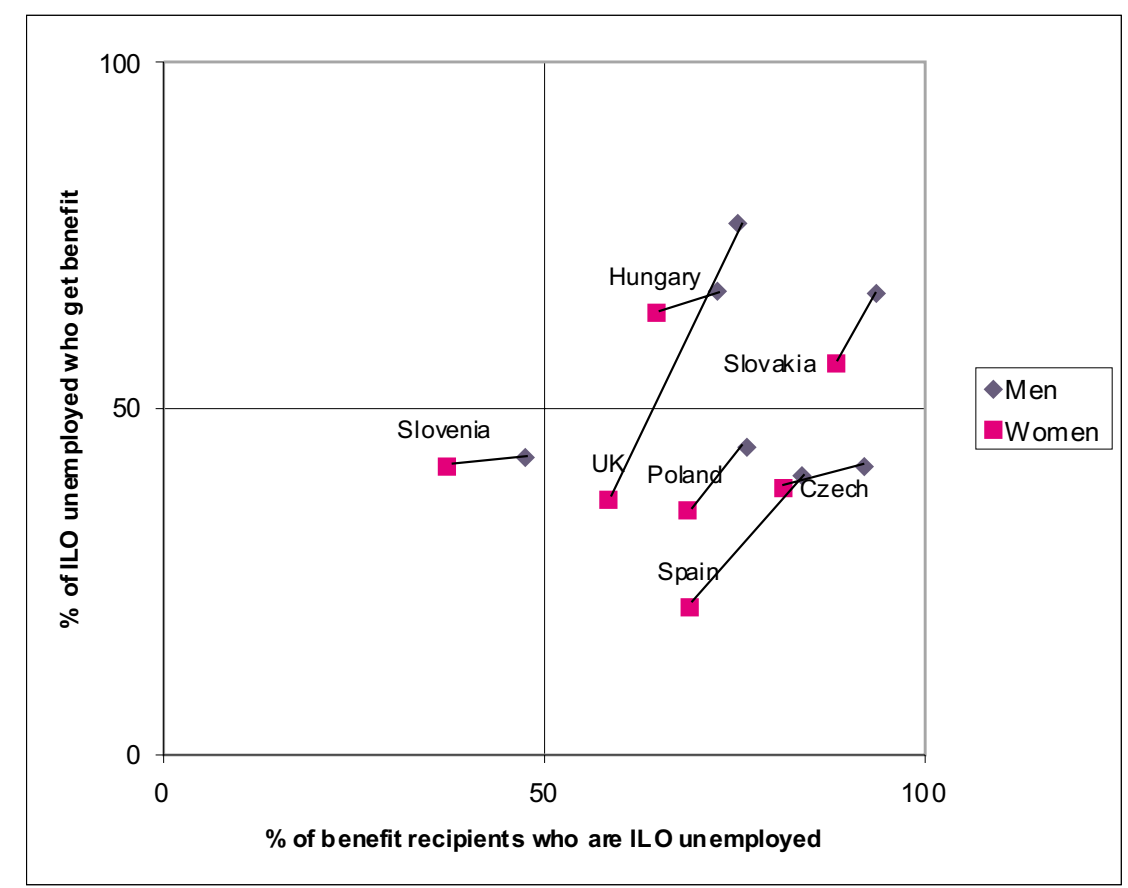

Figure 2. Targeting of unemployment benefit in different countries: all working age population

1 The sample sizes of ILO/OECD unemployed vary substantially from country to country on account of survey size as well as unemployment rate. The unemployment rates in Figure 1 are based on the following numbers of individuals classified as unemployed: Czech Republic, 1171; Hungary, 3554; Poland, 4189; Slovakia, 2007; Slovenia, 1023; Spain, 15751; UK, 5388. 
ILO/OECD unemployed that receive unemployment benefit while the horizontal axis shows the proportion with unemployment benefit that report having searched in the last month. In our terms, "good" targeting is associated with high values on both measures. "Unemployment benefit" includes both contributory unemployment insurance (UI) and means-tested "unemployment assistance" (UA) or its equivalent (any means-tested benefit paid to the unemployed that requires registration of unemployment status as a condition for eligibility). ${ }^{2}$ Although UI and UA are often combined in this way in analyses of unemployment benefit, the two are different in nature, both as regards the income support they provide and the effects on behaviour that can be expected (Atkinson and Micklewright, 1991). UI provides an incentive for formal employment: to maintain an insurance record to draw down on if need be at a later date. Means-tested UA constitutes a disincentive to the labour supply of other household members. UI typically provides a higher level of income support than UA (of course this may mean a greater disincentive to return to work). We distinguish between the two types of benefit later in the section.

The diagram includes separate results for men and women. The first obvious feature is that in each country the targeting of benefit is unambiguously worse for women - the data-point for women lies to the south-west of that for men in every case. Unemployed women are less likely to get benefit than men and among those with benefit they are less likely to be searching. However, the gender differences are notably greater for the two Western European countries. Twice as many men in the UK receive benefit as do women and the same is true in Spain although the absolute levels of receipt here are much lower. And in both countries the proportion of women with benefit who search is about 15 percent points less than for men. By contrast, the gender differences in the Central European countries are typically small. For example, the proportion of the unemployed getting benefit is very similar for the two sexes in Slovenia and the Czech Republic.

The second clear feature of the diagram is that only two countries are found in the north-east quadrant for both sexes, where targeting can be considered best;

2 This means that some means-tested benefits that the unemployed may receive on account of their low incomes alone, as opposed to a combination of low income and registration as unemployed, are not included. In the case of Poland this excludes one significant source of means-tested income support for the long-term unemployed; Gora and Schmidt (1998) report that 1 in 5 persons exhausting UI go on to receive means-tested social assistance, a benefit that does not require registration as unemployed. However, if we wish to analyse "unemployment benefit" it seems appropriate to restrict attention to those forms of income support in which registration of unemployment is a necessary condition for benefit. (Hence universal or means-tested family benefits, which may provide important income support to unemployed households with children, are excluded.) 
only in Hungary and Slovakia is it the case that both the majority of unemployed men and of unemployed women get benefit and that the majority of both sexes with benefit did search in the last month. The UK is in this quadrant for men but low benefit coverage pulls it down into the south-east quadrant in the case of women. Slovenia is the only country in the south-west quadrant where both coverage and search frequency are less than 50 percent. Viewed in this way, the Slovenian benefit system appears the least well targeted. Benefit coverage in Slovenia is similar to that in Poland and the Czech Republic (and also to that for Spanish men) - it is the low search propensity that singles out Slovenia. Overall, the levels of benefit coverage in these three Central European countries may come as some surprise - less than half the unemployed are receiving benefit.

One reason for the differences across country are the variation in the proportions of unemployed who have never worked or who have worked only a long time in the past, something associated with a low probability of coverage by insurance benefit. Figure 3 shows how the picture of targeting changes when we exclude those who have never worked or who last worked more than two years ago. In the case of the benefit recipients, the diagram also excludes those classified as employed on the ILO/OECD criteria. Questions on search are not asked of these

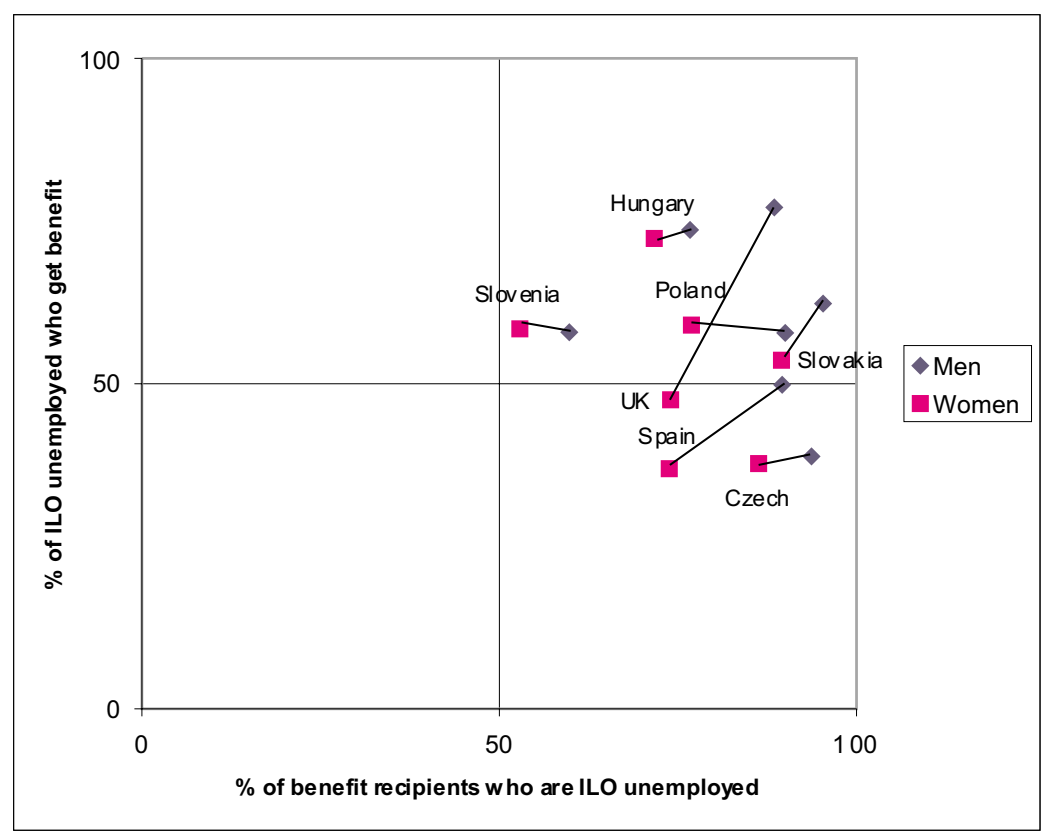

Figure 3. Targeting of unemployment benefit in different countries: those who have worked less than 2 years ago 
persons although some may in fact be legally receiving benefit while undertaking part-time work (as is allowed in Hungary for example).

The effect for most countries is to improve targeting, i.e. to move them towards the north-east. Slovenia and Poland now join Hungary and Slovakia in the north-east quadrant and women in the UK almost make it there to join their male counterparts. In five countries - the UK, Slovakia, Poland, Spain and the Czech Republic - the percentage of men with benefit who search is almost 90 percent or more and among men it is only Slovenia which appears much of an outlier.

These results refer to those persons performing any search and a key point here is that it includes persons whose only search in the previous month was a visit to the employment office. The questions on search in labour force survey questionnaires are structured in a way that they come separately from those on receipt of unemployment benefit. Respondents are asked whether they have searched in the last month and then about what methods of search were used, of which visiting the employment office is one. Nevertheless, the suspicion must remain that some of those reporting only that they searched via a visit to the employment office were in fact there primarily for their regular registration in order to collect unemployment benefit. This leads us to distinguish between "active" and "passive" search. We define active search as the use of any method other than visiting the employment office, which we label as being a passive method. The active methods are varied in nature and some (e.g. visiting employers) are clearly more active than others (e.g. checking newspaper advertisements). Nevertheless, this distinction serves to isolate those whose only action is to visit the state employment office, which they may do in any case to draw benefit.

It is active search that policy makers are typically most concerned to see occur. Search through public employment offices is often viewed as being rather ineffective. Benefit regulations in the UK require the unemployed receiving benefit to maintain a diary of their search activity that they may be called on to produce at any time. Such activity is presumed to include more than visiting the employment office.

Figure 4 shows the benefit targeting of active searchers - the proportion of those actively searching who get benefit and the proportion of those with benefit who actively search. In both cases the active search may be in conjunction with passive search - we are identifying those conducting any active search with or without passive search. However, in the case of the Czech Republic the coding of search methods is such that active search can be identified only if no passive search is conducted and for this reason this country is excluded from Figure 4.

Compared to Figure 3, the data-points shift to the left. The direction of change, of course, is clear a priori since a proportion of benefit recipients shown as searching in Figure 3 are only conducting passive search. The extent of this shift is not 


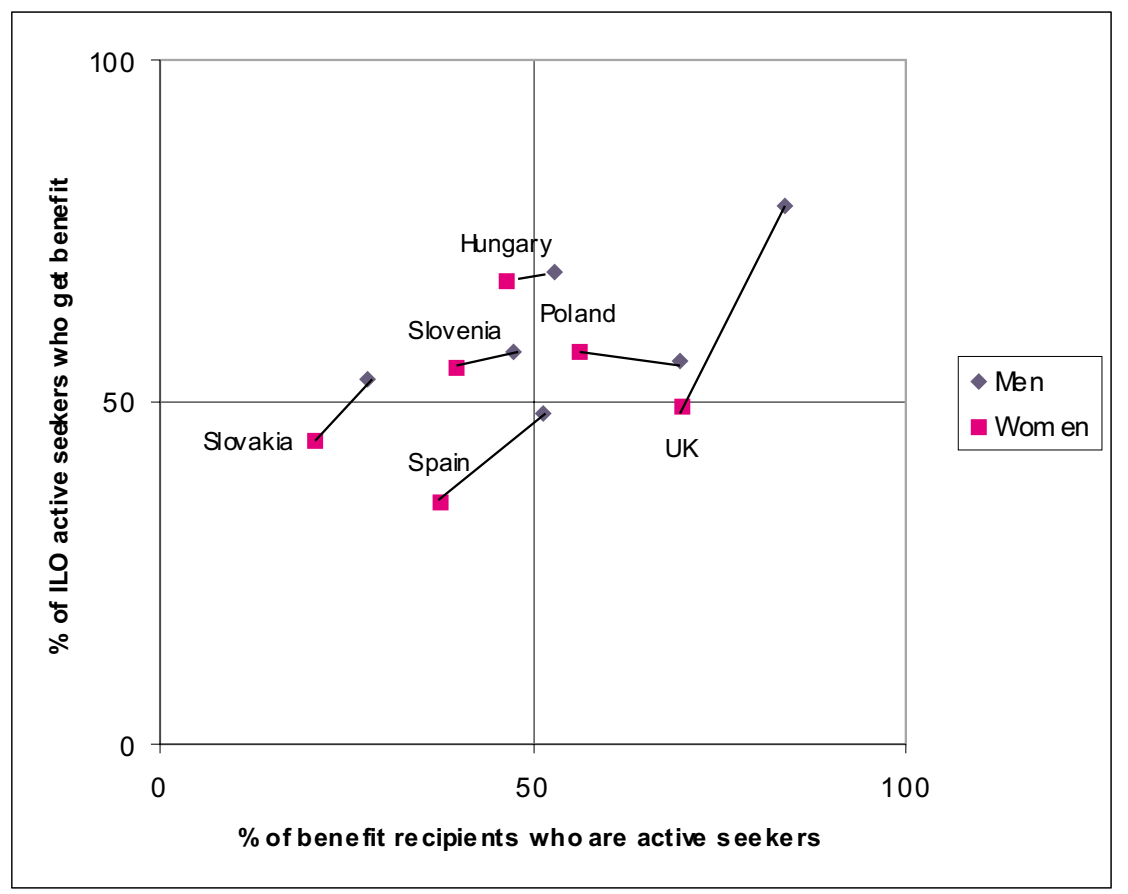

Figure 4. Active search and targeting of unemployment benefit in different countries: those who have worked less than 2 years ago

clear a priori and is large in several cases. Slovakia moves from being the country with the highest search frequency among benefit recipients in Figure 3 to being the lowest in Figure 4: only a quarter of benefit recipients conduct active search compared to around 90 percent who perform any form of search. Spain also shifts a long way to the left, while other countries experience only modest moves. In the case of Slovakia there must be some suspicion that the method of coding hides some active search; in this country only one search method is coded with the combination of active and passive search being one of the coded values. However, the practice followed in Spain of coding up to three separate search methods follows that in the other countries so no such possible explanation could apply here. The UK has the smallest move of all, implying that the great majority of benefit recipients who search are undertaking some form of active search. (The regulation in the UK that requires recipients to provide evidence of job search if required, which was mentioned above, should not be the reason since this was introduced after the year to which the UK data refer.)

By contrast with these horizontal shifts, the proportions of searchers receiving benefit - the figures on the vertical axis - change little from Figure 3. This implies 
that the proportion of the ILO/OECD unemployed who receive benefit is a good guide to the proportion of active searchers who are in receipt.

How does benefit receipt vary over duration of unemployment? ${ }^{3}$ One might assume that the shorter the duration of unemployment, the more likely the individual is to be receiving benefit, since UI entitlement will be less likely to have expired. This is certainly an assumption behind much discussion of unemployment benefit and the labour market. Figure 5, which restricted to the same sample as Figure 3, sheds light on the matter and provides some interesting results. Among men, the very short-term unemployed $-0-3$ months since last worked - are less likely to be in receipt of benefit that any other duration group, including those unemployed for over a year. This is true in all countries except Poland. The incidence of benefit is typically $10-20$ percent points lower at $0-3$ months than at $4-6$ months. A number of reasons may apply here including delays in claiming benefit at the start of the spell, and delays in eligibility due to a voluntary quit or severance pay.

The 4-6 month duration is where coverage for men is highest in 4 countries, the Czech Republic, Poland, Slovenia and Spain. In Hungary benefit coverage is highest in the 7-12 month group while in Slovakia and the UK it is highest for those unemployed over a year (those out of work for more than two years are excluded from the diagram). The results for women are similar although the lack of variation with duration in Spain and the UK now become even more pronounced.

To this point we have not distinguished between receipt of different types of unemployment benefit. But the distinction between UI and UA is an important one, as noted earlier. Table 1 shows how the type of benefit received by those working in the last 2 years. Spain is excluded from the table since the data for this country do not distinguish UI and UA. Poland is also excluded since at the time of

Table 1

Receipt of Unemployment Insurance and Unemployment Assistance benefits among the ILO/OECD unemployed

\begin{tabular}{lccccc}
\hline & Czech Rep. & Hungary & Slovakia & Slovenia & UK \\
\hline \% men with benefit & & & & & \\
Insurance (UI) & 15.0 & 70.1 & 15.8 & 45.7 & 55.6 \\
Assistance (UA) & 23.6 & 3.4 & 46.6 & 12.1 & 19.3 \\
\hline \% women with benefit & & & & & \\
Insurance (UI) & 17.3 & 70.1 & 15.2 & 41.9 & 32.9 \\
Assistance (UA) & 20.3 & 2.2 & 38.2 & 17.0 & 9.9 \\
\hline
\end{tabular}

3 In the paper we measure the duration of unemployment as time since the person last worked (and not as the duration of continuous job search). 
a) Men

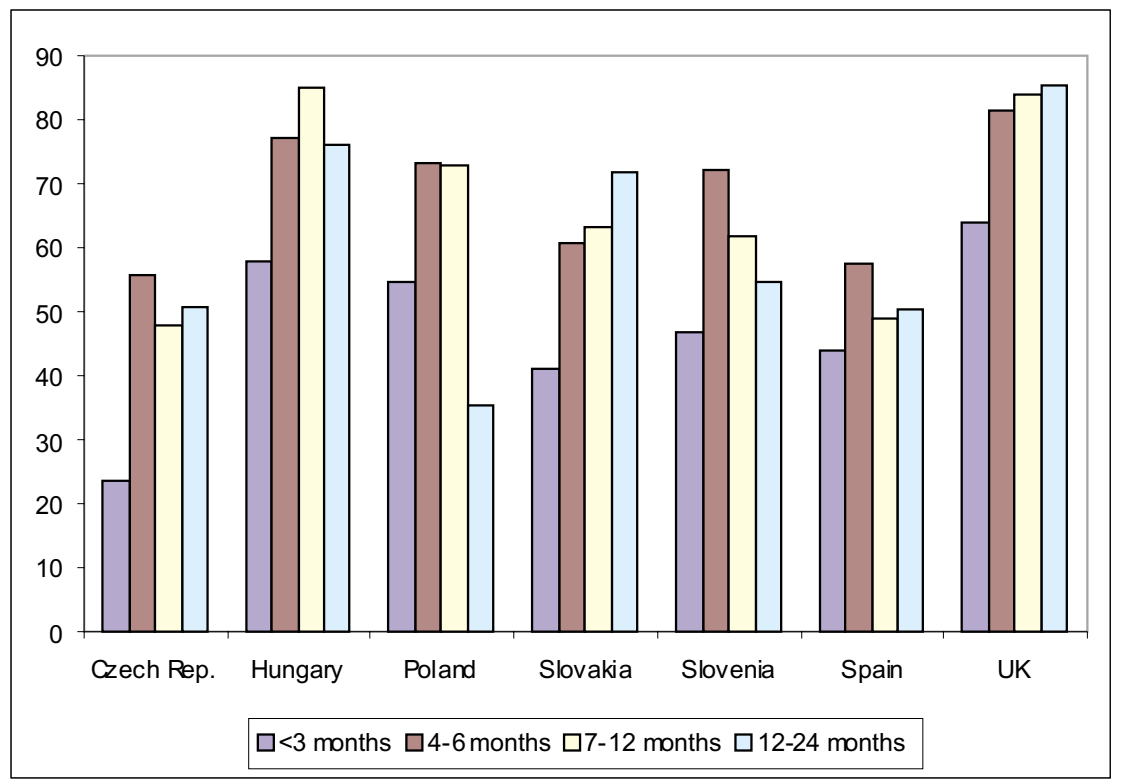

b) Women

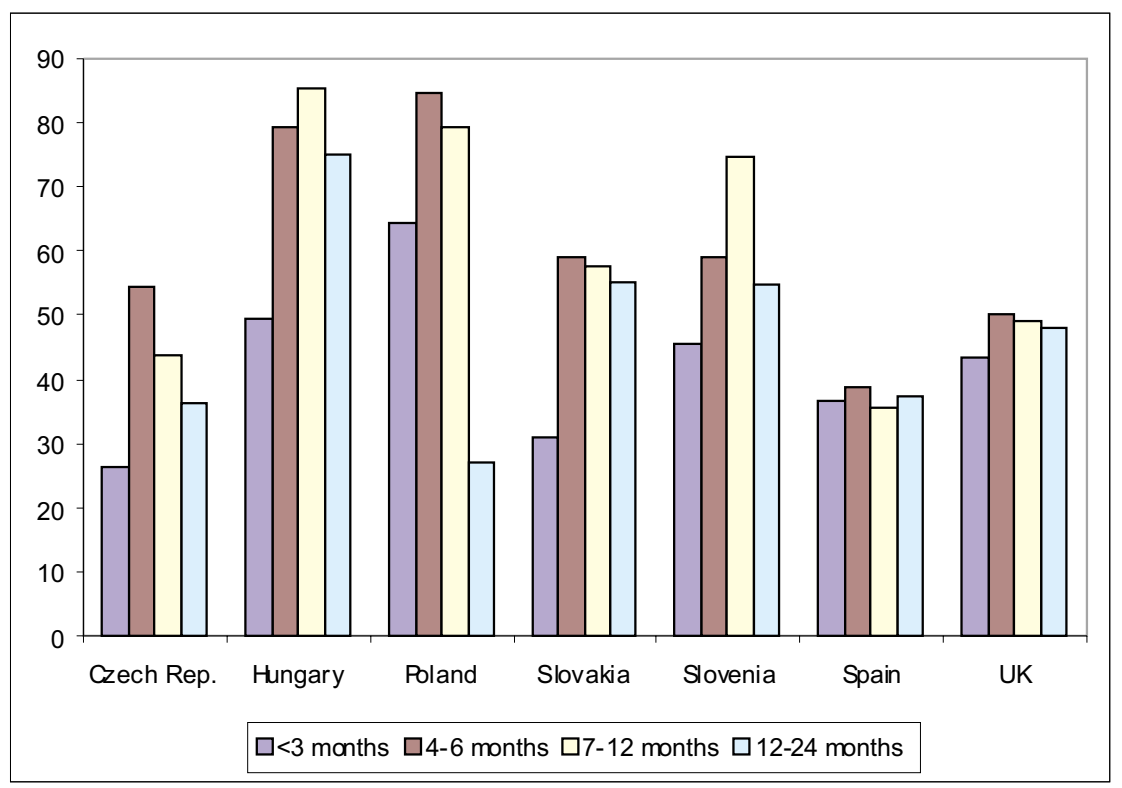

Figure 5. Unemployment benefit by time since last worked: ILO unemployed 
the data collected that are present in the LES there was no UA. ${ }^{4}$ The variation in the coverage of insurance benefit is striking. Whereas only 15 percent of the male ILO/OECD unemployed are shown receiving UI in the Czech Republic and in Slovakia, the figure is as high as 70 percent in Hungary (the figures for women are very similar).

How does Hungary emerge in general from these international comparisons? The lower coverage of women by benefits and the lower frequency of search by women receiving benefits is a feature shared with all the other countries included. The coverage of insurance benefit seems notably high in 1993, although as Section 4 makes clear this has since declined very sharply.

\section{DECOMPOSING DIFFERENCES IN BENEFIT COVERAGE}

In this section we consider how to investigate further one of the two key aspects of targeting, the proportion of searching unemployed who receive benefit. How should one try to isolate the effects of the various factors that change the coverage of unemployment benefit from country to country or over time? We observe that benefit coverage changes over time or across space but this could be due to differences in the composition of the unemployed (in terms of entitlement or claim behaviour) or to differences in the rules determining eligibility - or to some combination of the two.

The ideal approach would involve simulation with a benefit prediction model that incorporates differences in the rules determining eligibility. In this way we could - to take the case of changes over time - simulate coverage in year $t$ using the rules applying in year $t+d$ and hence accurately decompose the change in observed coverage between the two years into that part due to a change in rules and that part due to a change in the characteristics of the unemployed. Or, if the rules are fixed over time, changes in coverage could be decomposed into those arising from characteristics of the unemployed and those from claim behaviour. This is the approach adopted by Blank and Card (1991) in their analysis of changing coverage of insurance benefit in the USA. ${ }^{5}$

Unfortunately, labour force survey data do not contain sufficient detail for us to simulate benefit entitlement. We therefore adopt a different approach, attempting to decompose changes in coverage using multivariate analysis.

4 See footnote 2 for further information on means-tested benefit in Poland.

5 See also Creedy and Disney (1981) who simulate entitlements on assumed populations of the unemployed. 
Simplifying matters somewhat, the probability that an individual receives unemployment benefit can be written as a function of his or her work history and unemployment duration, which determines UI entitlement, and household income, which determines entitlement to UA.

$$
p(\text { benefit })=f(\text { work history, duration, household income }) .
$$

Most aspects of work history and household income are unobserved in the data to hand, but we observe various individual and household characteristics that influence them, including the age and education of the claimant and the number and type (including employment status) of other persons in the household.

$$
\begin{gathered}
\text { work history }=g_{1} \text { (observable characteristics) } \\
\text { household income }=g_{2} \text { (observable characteristics). }
\end{gathered}
$$

Hence we can estimate a model explaining the probability of benefit as a result of these characteristics and duration:

$$
p(\text { benefit })=h(\text { observable characteristics, duration }) .
$$

The function $h$ captures both function $f$ and functions $g_{1}$ and $g_{2}$.

Equation (4) could be estimated on data from different countries, as in the labour force survey data from the LES, or on data from one country drawn from different years. What would the estimated coefficients reveal? They will show the impact in country $j$ or year $t$ of observable individual and household characteristics and time spent unemployed on the probability of receiving benefit. These estimates will vary across country or across time either because the rules determining benefit differ (function $f$ ) or because the relationship between observable characteristics and unobservable work histories and household incomes differ (functions $g_{1}$ and $g_{2}$ ).

It is obvious that rules determining the impact of work history and household income vary substantially across countries; although they share some common general form, UI and UA schemes display considerable country-specific features. But it is also the case that the relationship transforming characteristics observable in labour force surveys into unobservable work histories and household incomes also vary from country to country. A young person of low education is likely to have a poorer work history than average in all countries but the extent to which this is the case is unlikely to be the same everywhere. Married women with young 
children are much more likely to have worked in the past in some countries than in others.

The differences in the functions $g_{1}$ and $g_{2}$ may be less over time within a given country but nevertheless can certainly be expected to occur. A particular constellation of observable characteristics in one year may be associated with a work history that is different to that several years later, especially when the nature of the labour market is changing, as in the transition countries of Central Europe. At the start of the transition there was little or no open unemployment and full employment had prevailed more or less for many years in most countries. Therefore differences in recent work histories across levels of education or between age groups were relatively small compared to the differences that can be expected in the mid and late 1990s given the concentration of unemployment on particular groups in the intervening years.

In what follows we estimate equation (4) by probit for Hungary alone for a series of years. We estimate equations using data from year $t+d$ and then use the results to predict entitlement for individuals observed in year $t$. The mean predicted probability in year $t$ using the year $t+d$ coefficients will give an unbiased estimate of the coverage of benefit in year $t$ were individuals to have received benefit determined as in year $t+d .^{6}$ In this way we can identify the extent to which changes in benefit coverage over time are explained by changes in observed characteristics, including the duration of unemployment. In particular this allows us to conclude whether the rise in long-term unemployment in Hungary has had much impact on benefit coverage.

\section{BENEFIT TARGETING IN HUNGARY}

In this section we investigate the changes that have taken place in benefit targeting in Hungary in the 1990s, using in part the framework described in the previous section. Figures 2-4 showed how targeting in Hungary in 1993 compared to that in other countries but it was noted that the picture could change over time. Here we address this issue directly.

The two parts of Figure 6 show how targeting of benefit changed between 1992 and 1997, distinguishing between men and women. Unemployment in Hungary on the ILO/OECD measure peaked in the 1990s in the first quarter of 1993 - the quarter of data in the LES database used in Section 2. Average unemployment in 1993 was 12 percent and it has since fallen reasonably steadily to 9 percent in

6 This follows the growth accounting technique derived in Gomulka and Stern (1990). 
a) All search

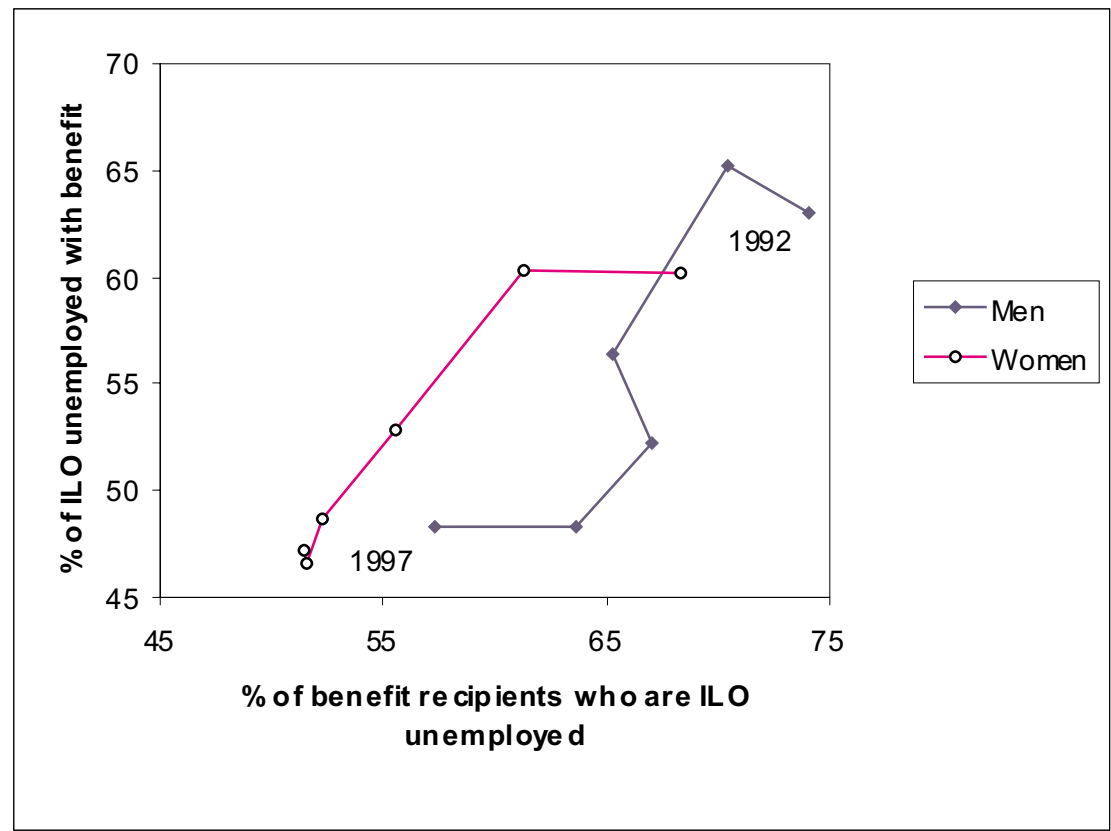

b) Active search

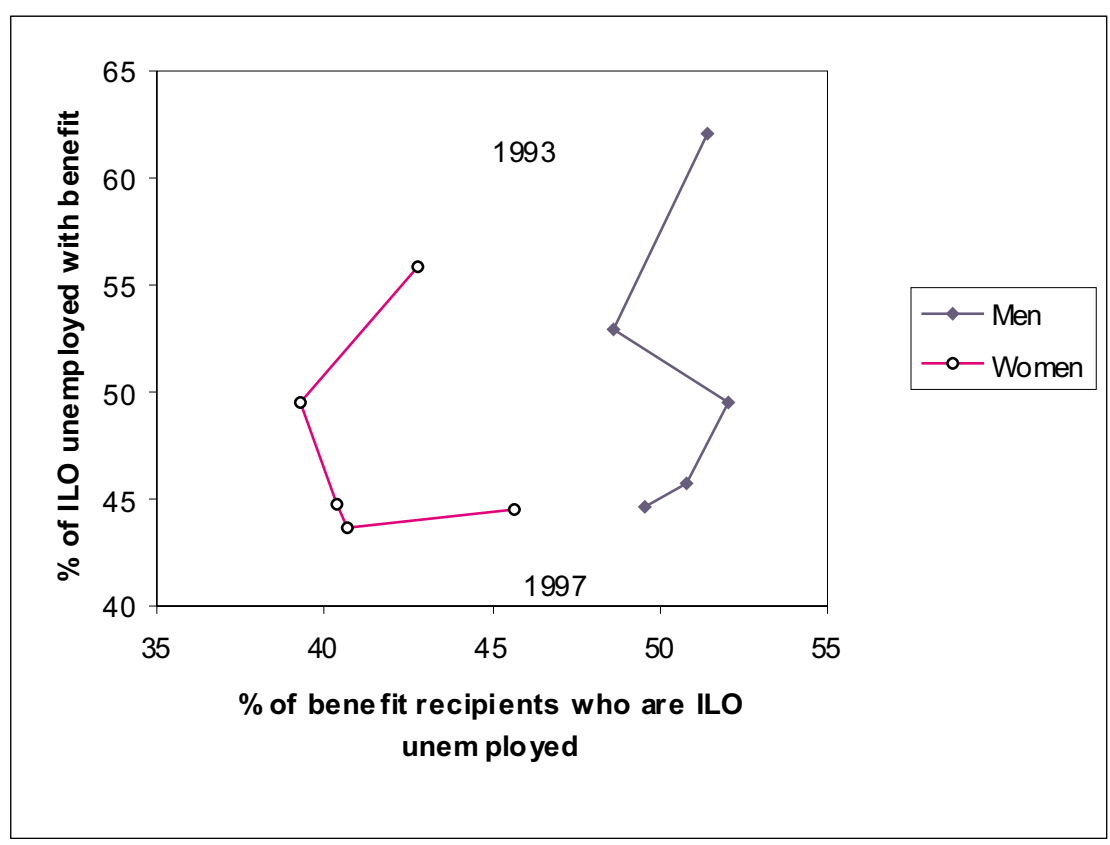

Figure 6. Targeting of unemployment benefit in Hungary, 1992-1997 
1997. The top half of Figure 6 focuses on all ILO/OECD unemployment and does not distinguish the two main types of benefit, UI and UA. Targeting appears to get unambiguously worse over the period, in that there is a move in the diagram towards the south-west. Whereas in 1992 some three-quarters of men with benefit were conducting search and over 60 percent of men who were unemployed on the ILO/OECD criteria received benefit, by 1997 these figures had fallen to 57 percent and 48 percent. ${ }^{7}$ In other words, not much more that half of men with benefit were searching and less than half of unemployed men were in receipt of any benefit. Similar falls are registered for women.

The bottom half of the diagram shows the changes when we restrict both axes to active search (with or without passive search). As already shown in the cross-national comparisons, the proportion of active searchers with benefit in Hungary in 1993 is not much different to that of all searchers and we see that again here in the data over time. Benefit coverage of active searchers falls with that of all searchers and by 1997 only 45 percent of active searchers of either sex receive any unemployment benefit.

By contrast, the proportion of benefit recipients who perform active search does not appear to fall - the general direction of the move in the bottom part of the diagram is towards the south rather than the south-west and in fact the figure for women is higher in 1997 than in 1992. Put another way, the leftward shift that is found in the proportion of benefit recipients who search when one moves from considering any search to active search gets less over time. Whereas in 1997, around 75 percent of male benefit recipients performed any search and 50 percent active search, by 1997 this gap had shrunk from this gap of 25 points to only 8 points.

The key change in the 1990s is therefore the reduction in benefit coverage of searchers and we now investigate that in more detail using the method outlined in the previous section.

Figure 6 conceals the fact that the fall in benefit coverage has been associated with a collapse in UI and a rise in the importance of UA. This is shown in Figure 7. Coverage by UI of the ILO/OECD unemployed falls from 60 percent in 1992, when it was the only benefit available, to only 23 percent in 1996 before recovering slightly to 25 percent in 1997. Almost identical coverage figures are found for men and women in 1997 - only a quarter of the ILO/OECD unemployed now receive insurance benefit. Figure 6 shows the rise in means-tested UA, which by 1997 had become as important a form of income support as UI.

7 The figures for 1993 differ from those for Hungary in Figure 2 since they refer to the whole year (in a period when coverage was declining) rather than to a single quarter. 
The discussion in Section 2 indicated why a switch in coverage from UI to UA should not be a matter of indifference. The relationship between UI and UA in Hungary follows the general characteristics of these two benefits in other countries: UA paid at a flat-rate amount provides substantially less income support to the majority of claimants than does earnings-related UI; it contains a very crude means-test, and it is administered by what are often very small local governments in a way that may both at times be somewhat arbitrary and that provides little monitoring of search (Micklewright and Nagy, 1998, 1999).

Besides coverage of benefit, Figure 7 also shows the marked rise in long-term unemployment in Hungary (persons searching for more than a year) from 15 percent in 1992 to 46 percent in 1996, something associated with the low turnover of the unemployed stock in Hungary as in other Central European countries (Boeri, 1994). Since UI is of limited duration, one's first thought might be that it is the lengthening durations of the unemployed that have been mainly to blame for the collapse in UI coverage. However, the story is more complicated than this. It is also the case that the 1990s have seen a reduction in entitlement periods for UI. For successful claims to UI starting before the end of 1992, eligibility was for between a minimum of 4.5 months and a maximum of 18 months, the former brought about by one year's insured employment in the last four years and the latter by a continuous work history within this period, with entitlement varying between the two extremes for intermediate work histories. For new claims from

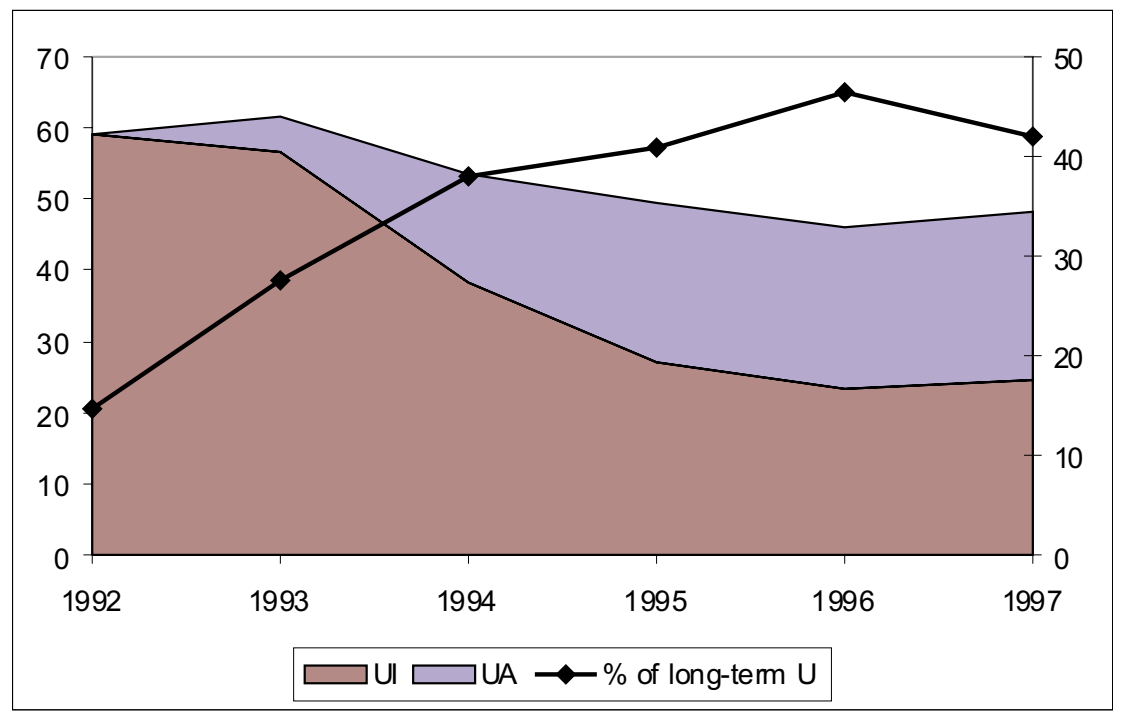

Figure 7. Changing coverage of UI and UA of the ILO/OECD unemployed in Hungary 
Table 2

Probit estimates of UI and UA receipt among the ILO/OECD unemployed in Hungary

a) Men

\begin{tabular}{|c|c|c|c|c|c|c|c|c|}
\hline & \multicolumn{4}{|c|}{ Probability of UI receipt } & \multicolumn{4}{|c|}{ Probability of UA receipt } \\
\hline & \multicolumn{2}{|c|}{1993} & \multicolumn{2}{|c|}{1997} & \multicolumn{2}{|c|}{1993} & \multicolumn{2}{|c|}{1997} \\
\hline & Coef. & $z$ & Coef. & $z$ & Coef. & $z$ & Coef. & $z$ \\
\hline \multicolumn{9}{|l|}{ Educational level } \\
\hline incomplete primary & 0.083 & 0.67 & -0.286 & -1.18 & 0.246 & 1.49 & 0.379 & 2.14 \\
\hline vocational & 0.172 & 2.98 & 0.133 & 1.63 & -0.335 & -3.26 & -0.212 & -2.74 \\
\hline general secondary & 0.006 & 0.05 & 0.244 & 1.71 & -0.189 & -0.82 & -0.366 & -2.28 \\
\hline vocational secondary & 0.045 & 0.52 & 0.209 & 1.65 & -0.136 & -0.86 & -0.360 & -2.67 \\
\hline higher & -0.220 & -1.45 & 0.073 & 0.29 & 0.061 & 0.22 & -0.643 & -2.19 \\
\hline \multicolumn{9}{|l|}{ Age-group (years) } \\
\hline-19 & -0.459 & -4.05 & -0.574 & -3.08 & 0.047 & 0.21 & -0.815 & -3.85 \\
\hline $20-29$ & -0.103 & -1.42 & 0.066 & 0.62 & 0.113 & 0.98 & -0.267 & -2.64 \\
\hline $40-49$ & -0.007 & -0.09 & 0.203 & 1.95 & -0.189 & -1.47 & 0.015 & 0.16 \\
\hline $50-59$ & 0.244 & 2.25 & 0.164 & 1.11 & -0.318 & -1.66 & -0.018 & -0.14 \\
\hline \multicolumn{9}{|l|}{ Months since last employment } \\
\hline 1 & -1.007 & -9.47 & -0.316 & -2.22 & -0.377 & -1.28 & -0.866 & -3.21 \\
\hline $2-3$ & -0.336 & -4.09 & -0.034 & -0.31 & -0.126 & -0.47 & -0.077 & -0.56 \\
\hline $10-12$ & 0.233 & 2.17 & -0.134 & -0.95 & 0.150 & 0.62 & 0.439 & 2.71 \\
\hline $13-24$ & -0.464 & -6.88 & -0.968 & -9.39 & 1.035 & 6.39 & 0.810 & 7.37 \\
\hline$>24$ & -1.601 & -15.72 & -1.684 & -14.64 & 1.564 & 8.83 & 0.737 & 7.16 \\
\hline never worked & -1.357 & -12.39 & -1.223 & -7.95 & -0.131 & -0.43 & -0.231 & -1.27 \\
\hline \multicolumn{9}{|l|}{ Household circumstances } \\
\hline Married & 0.064 & 0.92 & 0.085 & 0.91 & 0.077 & 0.65 & 0.173 & 1.93 \\
\hline No. of children & -0.003 & -0.08 & -0.030 & -0.67 & 0.054 & 1.02 & -0.024 & -0.56 \\
\hline No. of employed & -0.033 & -1.03 & 0.000 & 0.01 & -0.175 & -2.67 & -0.159 & -3.26 \\
\hline No. of pensioners & -0.067 & -1.59 & -0.021 & -0.38 & -0.010 & -0.13 & -0.083 & -1.53 \\
\hline No. of other persons & -0.031 & -0.92 & -0.127 & -2.47 & -0.018 & -0.34 & -0.029 & -0.66 \\
\hline 0-3 years old child (dummy) & -0.072 & -0.84 & 0.112 & 0.92 & 0.006 & 0.05 & 0.039 & 0.34 \\
\hline 4-6 years old child (dummy) & 0.087 & 0.98 & 0.162 & 1.44 & -0.110 & -0.75 & -0.055 & -0.50 \\
\hline \multicolumn{9}{|l|}{ Region } \\
\hline Budapest & -0.411 & -4.46 & -0.324 & -2.32 & -0.777 & -2.89 & -0.244 & -1.70 \\
\hline High unemployment region & 0.125 & 1.99 & -0.376 & -4.43 & 0.297 & 3.19 & 0.641 & 8.34 \\
\hline Low unemployment region & 0.061 & 0.69 & -0.232 & -1.84 & -0.832 & -2.82 & -0.049 & -0.36 \\
\hline Constant & 0.823 & 8.14 & 0.019 & 0.13 & -2.082 & -10.27 & -0.878 & -5.97 \\
\hline Log-likelihood & \multicolumn{2}{|c|}{-1785.2855} & \multicolumn{2}{|c|}{-878.85839} & \multicolumn{2}{|c|}{-527.57093} & \multicolumn{2}{|c|}{-915.40633} \\
\hline Pseudo $\mathrm{R}^{2}$ & \multicolumn{2}{|c|}{0.1814} & \multicolumn{2}{|c|}{0.2319} & \multicolumn{2}{|c|}{0.2619} & \multicolumn{2}{|c|}{0.1984} \\
\hline No. of observations & \multicolumn{2}{|c|}{3239} & \multicolumn{2}{|c|}{2049} & \multicolumn{2}{|c|}{3239} & \multicolumn{2}{|c|}{2049} \\
\hline
\end{tabular}


(Table 2, continued)

b) Women

\begin{tabular}{|c|c|c|c|c|c|c|c|c|}
\hline & \multicolumn{4}{|c|}{ Probability of UI receipt } & \multicolumn{4}{|c|}{ Probability of UA receipt } \\
\hline & \multicolumn{2}{|c|}{1993} & \multicolumn{2}{|c|}{1997} & \multicolumn{2}{|c|}{1993} & \multicolumn{2}{|c|}{1997} \\
\hline & Coef. & $z$ & Coef. & $z$ & Coef. & $z$ & Coef. & $z$ \\
\hline \multicolumn{9}{|l|}{ Educational level } \\
\hline incomplete primary & 0.048 & 0.30 & -0.783 & -2.14 & 0.241 & 1.11 & 0.685 & 3.36 \\
\hline vocational & 0.094 & 1.08 & 0.243 & 2.10 & 0.014 & 0.09 & -0.019 & -0.17 \\
\hline general secondary & 0.020 & 0.19 & 0.236 & 1.72 & 0.228 & 1.28 & -0.274 & -1.85 \\
\hline vocational secondary & -0.170 & -1.66 & 0.321 & 2.41 & -0.082 & -0.40 & -0.287 & -1.99 \\
\hline higher & -0.352 & -1.83 & 0.554 & 2.35 & -0.072 & -0.19 & -1.171 & -3.03 \\
\hline \multicolumn{9}{|l|}{ Age-group (years) } \\
\hline-19 & -0.787 & -5.26 & -0.320 & -1.50 & -0.090 & -0.31 & -1.022 & -3.71 \\
\hline $20-29$ & -0.219 & -2.29 & 0.040 & 0.31 & 0.010 & 0.06 & -0.269 & -2.06 \\
\hline $40-49$ & 0.043 & 0.45 & 0.161 & 1.23 & -0.207 & -1.24 & 0.067 & 0.54 \\
\hline $50-59$ & -0.082 & -0.50 & 0.107 & 0.45 & -0.624 & -1.65 & -0.113 & -0.52 \\
\hline \multicolumn{9}{|l|}{ Months since last employment } \\
\hline 1 & -1.002 & -6.38 & -0.159 & -0.80 & 0.343 & 0.67 & -0.846 & -2.43 \\
\hline $2-3$ & -0.490 & -3.72 & -0.009 & -0.06 & 0.031 & 0.06 & -0.244 & -1.25 \\
\hline $10-12$ & 0.214 & 1.31 & -0.010 & -0.05 & 0.185 & 0.36 & 0.242 & 1.12 \\
\hline $13-24$ & -0.482 & -4.38 & -1.015 & -6.20 & 1.312 & 3.64 & 0.759 & 4.99 \\
\hline$>24$ & -1.438 & -11.26 & -1.423 & -9.05 & 1.548 & 4.20 & 0.530 & 3.86 \\
\hline never worked & -1.599 & -10.45 & -1.326 & -6.30 & 0.429 & 1.00 & -0.355 & -1.51 \\
\hline \multicolumn{9}{|l|}{ Household circumstances } \\
\hline Married & & & & & & & & \\
\hline No. of children & 0.157 & 1.88 & 0.017 & 0.15 & -0.143 & -0.98 & 0.027 & 0.24 \\
\hline No. of employed & -0.070 & -1.61 & -0.001 & -0.02 & -0.043 & -0.58 & -0.048 & -0.79 \\
\hline No. of pensioners & 0.101 & 2.12 & 0.135 & 2.30 & -0.214 & -2.33 & -0.313 & -4.58 \\
\hline No. of other persons & 0.015 & 0.25 & 0.014 & 0.18 & -0.015 & -0.13 & -0.089 & -1.10 \\
\hline $0-3$ years old child (dummy) & -0.058 & -1.22 & -0.088 & -1.29 & 0.055 & 0.66 & 0.092 & 1.42 \\
\hline 4-6 years old child (dummy) & -0.353 & -2.56 & 0.419 & 2.16 & -0.394 & -1.41 & -0.371 & -1.75 \\
\hline Region & 0.554 & 5.64 & 0.605 & 4.54 & -0.339 & -1.87 & -0.026 & -0.19 \\
\hline Budapest & -0.535 & -4.95 & -0.194 & -1.35 & -0.396 & -1.65 & -0.546 & -3.15 \\
\hline High unemployment region & 0.031 & 0.37 & -0.258 & -2.14 & -0.014 & -0.10 & 0.504 & 4.59 \\
\hline Low unemployment region & -0.144 & -1.12 & 0.117 & 0.75 & 0.059 & 0.24 & -0.283 & -1.47 \\
\hline Constant & 0.873 & 5.84 & -0.296 & -1.53 & -2.274 & -5.70 & -0.576 & -3.10 \\
\hline Log-likelihood & \multicolumn{2}{|c|}{-996.96238} & \multicolumn{2}{|c|}{-542.32972} & \multicolumn{2}{|c|}{-283.20324} & \multicolumn{2}{|c|}{-520.59461} \\
\hline Pseudo $R^{2}$ & \multicolumn{2}{|c|}{0.2507} & \multicolumn{2}{|c|}{0.2279} & \multicolumn{2}{|c|}{0.1815} & \multicolumn{2}{|c|}{0.2217} \\
\hline No. of observations & \multicolumn{2}{|c|}{1943} & \multicolumn{2}{|c|}{1228} & \multicolumn{2}{|c|}{1943} & \multicolumn{2}{|c|}{1228} \\
\hline
\end{tabular}


1993, entitlement periods were cut by one third, hence to a total of between 3 and 12 months.

Using the framework in Section 3, we now try to shed light on the importance of lengthening unemployment durations (and changes in other observed characteristics) in explaining changes in the coverage of UI and UA. For each gender and for each year, we estimate equation (4) by probit for UI and UA separately for all ILO/OECD unemployed. The two benefits are mutually exclusive - UA can only be received by someone who has exhausted UI entitlement in the current or a previous spell. Following the discussion of Section 3, the equations contain explanatory variables for age, duration of unemployment, household status (numbers and types of other household members), and region. The results for men for 1993 and 1997 are given in Table 2.

We go on to predict the probability of receipt of the two benefits for the 1993 sample using the coefficients of the other years and then calculate the mean probabilities of receipt. This leads to the "predicted" frequencies of receipt that are given alongside the actual sample frequencies for each year in Table $3 .{ }^{8}$ The "predicted" frequencies in Table 3 show receipt holding constant observable characteristics at their 1993 values. As discussed in section 3, the probit coefficients for each year summarise the rules determining entitlement - function $f$ - and the links between the unobserved work histories and household incomes on the one hand and observed individual and household characteristics on the other - functions $g_{1}$ and $g_{2}$. As argued in section 3, the latter can be expected to have changed as well as the former.

The results in Table 2 show some clear patterns together with others that are less easy to interpret. The impact of education on the probability of UI is clearest for women in 1997. The base group is completed primary school and persons with levels of education above this are significantly more likely to get benefit while those who did not complete primary school are less likely. There appears to have been a clear increase in the link between education and UI between 1993 and 1997, which we interpret as reflecting the development of poorer work histories during the intervening years for those with less education. The results for men follow a similar pattern although less obviously. We give the same interpretation to the big change in the coefficient on the dummy variable indicating residence in one of the three high unemployment regions. By 1993, residence in one of these

8 The samples used in estimation are all those from the first quarter of each year plus those new entrants to the survey found in the stock in later quarters. The labour force survey has a quarterly rotating panel design with 5/6ths of the sample remaining in the survey each quarter. The "actual" figures for each year therefore differ somewhat from those in Figure 6 which are an average of the separate figures for each full quarter. 
Table 3

Actual and predicted benefit coverage among ILO/OECD unemployed in Hungary

a) Unemployment insurance

\begin{tabular}{|c|c|c|c|c|}
\hline \multirow[t]{3}{*}{ Year } & \multicolumn{4}{|c|}{ The probability of UI receipt (ILO unemployed) } \\
\hline & \multicolumn{2}{|c|}{ Men } & \multicolumn{2}{|c|}{ Women } \\
\hline & actual & fitted & actual & fitted \\
\hline 1992 & 61.4 & 59.6 & 58.3 & 57.6 \\
\hline 1993 & 59.9 & 59.9 & 56.5 & 56.5 \\
\hline 1994 & 39.3 & 45.3 & 39.9 & 44.8 \\
\hline 1995 & 26.6 & 35.5 & 28.5 & 32.3 \\
\hline 1996 & 22.0 & 30.6 & 26.1 & 31.7 \\
\hline 1997 & 24.6 & 31.1 & 25.7 & 30.3 \\
\hline
\end{tabular}

b) Unemployment assistance

\begin{tabular}{|c|c|c|c|c|}
\hline \multirow[t]{3}{*}{ Year } & \multicolumn{4}{|c|}{ The probability of UA receipt (ILO unemployed) } \\
\hline & \multicolumn{2}{|c|}{ Men } & \multicolumn{2}{|c|}{ Women } \\
\hline & actual & fitted & actual & fitted \\
\hline 1993 & 5.8 & 5.8 & 4.3 & 4.3 \\
\hline 1994 & 16.8 & 13.2 & 13.3 & 12.3 \\
\hline 1995 & 24.5 & 19.0 & 19.9 & 18.4 \\
\hline 1996 & 25.1 & 19.6 & 20.0 & 18.1 \\
\hline 1997 & 24.5 & 22.7 & 23.3 & 23.6 \\
\hline
\end{tabular}

regions indicates a weaker employment history or prior receipt of UI (which uses up entitlement). Duration of employment clearly has a change in impact between the two years (as one would expect from changing rules of entitlement). At durations of under a year the variation of benefit with duration becomes notably less marked for both sexes. Many of the household circumstance variables have little or no impact, except it is clear that other employed persons in the household reduces the probability of receiving UA, an effect that operates through the household means-test.

The results in Table 3 show clearly that changes in the composition of observed characteristics of the unemployed, including time since last worked, do not explain most of the fall in the coverage of UI or the rise in coverage of UA. Holding observed characteristics constant at their 1993 levels, UI coverage for men falls from 60 percent in this year to 31 percent in 1997, compared to the actual fall to 25 percent. Similarly, predicted coverage for women falls from 57 percent to 30 percent compared to an actual fall to 26 percent. Predicted UA coverage in 1997 for 
men is 23 percent and 24 percent for women, compared to actual coverage of 25 percent and 23 percent respectively, up from figures of only 6 and 4 percent in 1993. The conclusion is therefore that the big changes in benefit coverage in Hungary in the 1990s have had relatively little to do with the changing composition of the unemployed in terms of duration of unemployment, age, education or household composition.

The relative importance of changes in rules of entitlement and changes in the work histories and incomes that generate entitlement is, however, impossible to tell from the results. Existing claims to UI in progress in January 1993 were "grandfathered" under the old entitlement rules and therefore the impact of the introduction of the new rules on coverage in the stock was far from sudden.

\section{Search propensity}

We have already noted that the change over time in the proportion of benefit recipients that undertake active search is quite small. One important policy issue, however, relates to any differences in the frequency of search between those receiving UI and UA. UA is administered (and part-funded) in Hungary by local governments, many of which are far too small to have any real capability to monitor search behaviour of claimants. (Local governments have an average population of only 3,000 people.) UA recipients must retain their registration of unemployment at the local unemployment office but beyond this minimal requirement there appears in many cases to be very little contact between any organ of central or local government and the claimant after the outcome of an application for benefit has been determined (Micklewright and Nagy, 1998, 1999). One of the concerns expressed by policy makers in Hungary is that, as a result, UA represents "easy money" for the unemployed.

The unconditional probability of active search does vary between the two types of benefit recipient but the differences are not great. In 1997, the proportions of UI and UA recipients conducting active search were 53 percent and 46 percent for men and 47 percent and 43 percent for women (see Figure 6). Active search is thus somewhat more common for those on UI. These figures are averages of separate quarterly data; when we use the same microdata samples of benefit recipients as enter the estimation of the models in Table 2, we find that differences in the probability of active search between the two groups of recipients that are insignificant. ${ }^{9}$

Table 4 shows the results of probit equations of the probabilities of active search for the two types of recipient, estimated with 1997 data when the UI and

9 See footnote 8 on the selection of the sample in Table 2. 
Table 4

Probit estimates of active search for 1997 in Hungary

\begin{tabular}{|c|c|c|c|c|c|c|c|c|}
\hline & \multicolumn{4}{|c|}{ Men } & \multicolumn{4}{|c|}{ Women } \\
\hline & \multicolumn{2}{|c|}{ UI recipients } & \multicolumn{2}{|c|}{ UA recipients } & \multicolumn{2}{|c|}{ UI recipients } & \multicolumn{2}{|c|}{ UA recipients } \\
\hline & Coef. & $z$ & Coef. & $z$ & Coef. & $z$ & Coef. & $z$ \\
\hline \multicolumn{9}{|l|}{ Educational level } \\
\hline incomplete primary & -0.049 & -0.18 & -0.316 & -1.81 & -0.084 & -0.19 & -0.053 & -0.28 \\
\hline vocational & 0.334 & 3.05 & 0.241 & 2.41 & 0.269 & 1.89 & 0.160 & 1.14 \\
\hline general secondary & 0.837 & 3.92 & 0.545 & 2.05 & 0.076 & 0.46 & 0.160 & 0.82 \\
\hline vocational secondary & 0.305 & 1.82 & 0.589 & 2.85 & 0.363 & 2.11 & 0.277 & 1.36 \\
\hline higher & 0.172 & 0.48 & -0.403 & -0.78 & 1.171 & 3.28 & 0.140 & 0.28 \\
\hline \multicolumn{9}{|l|}{ Age-group (years) } \\
\hline-19 & -0.023 & -0.08 & 0.576 & 1.19 & -0.135 & -0.37 & 0.148 & 0.35 \\
\hline $20-29$ & 0.164 & 1.15 & 0.095 & 0.75 & -0.185 & -1.15 & 0.066 & 0.43 \\
\hline $40-49$ & 0.098 & 0.71 & -0.059 & -0.50 & -0.076 & -0.46 & 0.243 & 1.70 \\
\hline $50-59$ & -0.610 & -3.39 & -0.166 & -1.05 & -0.946 & -3.37 & 0.022 & 0.09 \\
\hline \multicolumn{9}{|l|}{ Months since last employment } \\
\hline 1 & -0.395 & -2.22 & 0.001 & 0.00 & -0.075 & -0.33 & -0.473 & -0.67 \\
\hline $2-3$ & -0.323 & -2.28 & 0.270 & 1.05 & 0.050 & 0.27 & -0.011 & -0.04 \\
\hline $7-9$ & 0.041 & 0.24 & 0.215 & 0.82 & -0.245 & -1.18 & -0.242 & -0.74 \\
\hline $10-12$ & -0.123 & -0.68 & 0.720 & 2.63 & -0.007 & -0.03 & 0.321 & 0.99 \\
\hline $13-24$ & -0.238 & -1.42 & 0.409 & 1.94 & -0.187 & -0.90 & 0.111 & 0.47 \\
\hline$>24$ & -0.358 & -1.69 & 0.282 & 1.37 & -0.409 & -1.98 & -0.029 & -0.13 \\
\hline never worked & -0.483 & -1.65 & 0.258 & 0.75 & -0.144 & -0.40 & -0.274 & -0.75 \\
\hline \multicolumn{9}{|l|}{ Household circumstances } \\
\hline Married & -0.093 & -0.73 & 0.194 & 1.71 & -0.175 & -1.28 & 0.039 & 0.29 \\
\hline No. of children & -0.015 & -0.24 & -0.122 & -2.27 & -0.022 & -0.26 & -0.026 & -0.41 \\
\hline No. of employed & -0.014 & -0.24 & 0.102 & 1.48 & -0.009 & -0.14 & -0.183 & -2.14 \\
\hline No. of pensioners & -0.153 & -2.00 & -0.039 & -0.55 & 0.033 & 0.33 & -0.191 & -2.02 \\
\hline No. of other persons & -0.024 & -0.33 & 0.007 & 0.13 & -0.125 & -1.34 & 0.007 & 0.10 \\
\hline $0-3$ years old child (dummy) & 0.036 & 0.22 & -0.001 & 0.00 & -0.090 & -0.40 & -0.418 & -1.81 \\
\hline 4-6 years old child (dummy) & -0.039 & -0.27 & 0.170 & 1.20 & 0.114 & 0.70 & 0.033 & 0.21 \\
\hline \multicolumn{9}{|l|}{ Region } \\
\hline Budapest & 0.838 & 3.34 & 0.820 & 2.86 & 0.553 & 2.64 & 0.357 & 1.17 \\
\hline High unemployment region & -0.128 & -1.13 & 0.112 & 1.17 & -0.385 & -2.72 & -0.106 & -0.89 \\
\hline Low unemployment region & 0.305 & 1.67 & 0.114 & 0.57 & 0.284 & 1.61 & -0.186 & -0.67 \\
\hline Constant & 0.195 & 1.00 & -0.574 & -2.38 & 0.098 & 0.40 & -0.138 & -0.51 \\
\hline Log-likelihood & \multicolumn{2}{|c|}{-504.96703} & \multicolumn{2}{|c|}{-579.07122} & \multicolumn{2}{|c|}{-370.8122} & \multicolumn{2}{|c|}{-384.7011} \\
\hline Pseudo $\mathrm{R}^{2}$ & \multicolumn{2}{|c|}{0.0833} & \multicolumn{2}{|c|}{0.0537} & \multicolumn{2}{|c|}{0.0911} & \multicolumn{2}{|c|}{0.0379} \\
\hline No. of observations & \multicolumn{2}{|c|}{798} & \multicolumn{2}{|c|}{883} & \multicolumn{2}{|r|}{596} & \multicolumn{2}{|c|}{586} \\
\hline
\end{tabular}

UA were broadly of equal importance in terms of benefit coverage. Likelihood ratio tests of these separate models against a pooled model with both benefit types taken together result in failure to reject the pooled models, confirming that the dif- 
ferences between search propensity of individuals on the two types of benefit are not great. Nevertheless, some differences emerge and the results also reveal some patterns of active search that are common to the two sexes.

Among men, all education levels beyond primary (the base) are associated with more search, with the exception, surprisingly, of higher education (the sample numbers are small in this case). The differences by education group are less evident for women. UI recipients aged 50 or over of both sexes are less likely to search but the same is not true of those of this age on UA. This may be because many persons on UI within 5 years of retirement age leave UI for an early retirement scheme and hence do not search while on UI. But conditional on their not entering this scheme and then moving onto UA, their age has no impact on their search activity. The search probability clearly varies with duration for men, first rising and then falling, although the effects are not very well determined. The results for women, however, do not really display this pattern. The household circumstance variables have little impact for either sex and for either benefit, which comes as some surprise. Perhaps the most notable results are the lack of much impact of the presence of young children for women (the dummy for a child aged 0-3 is only significant at the 10 percent for women) and the negative impact (significant at the 5 percent level) of employed people in the household on active search by women receiving UA, but not those receiving UA.

\section{CONCLUSIONS}

In this paper we have proposed two measures to be used when considering coverage of unemployment benefit systems. These are linked to the measurement of job search behaviour - the percentage of those without work who search who receive unemployment benefits and the percentage of those with unemployment benefits who do undertake search. Using these we have generated some stylised facts about benefit coverage in Central Europe in the 1990s, taking the UK and Spain as EU comparators. And we have investigated changing coverage in Hungary, proposing a framework for doing so that could also be used in cross-national comparisons so as to control for variation in the observed composition of the unemployed. Our principal findings include:

- Less than half of the searching unemployed in 3 of the 5 Central European countries observed in 1993-95 received unemployment benefit. In the case of men, this is a much lower figure than for the UK in 1989 but is similar to that found for Spanish men in 1993. Coverage was higher in Hungary and Slovakia. 
- The proportion of benefit recipients recording search in the Central European countries exceeded half in all cases, except Slovenia and is comparable to that in the UK and Spain.

- The targeting of benefit on women is worse than that for men in all countries considered; fewer searching women receive benefit and fewer women with benefit do search. The differences were particularly marked in the two EU comparators.

- The proportion of those actively searching who receive benefits appears in general to differ little from the percentage of all searchers receiving benefits (including those undertaking only passive search, defined as visiting public employment offices).

- Among those receiving benefits, the coverage of contributory UI and means-tested UA varied quite sharply. The coverage of UI was already very low in the Czech Republic and Slovakia in 1994-95 - only 15 percent of searchers in receipt - well below the level observed in the UK.

- Benefit coverage of searchers in Hungary fell to around 50 percent by 1996-97 from around 60 percent in 1992. The proportion of those with benefit who performed any search also fell, but the propensity to search actively did not.

- Coverage by UI of searchers in Hungary by fell by some 35 percent points over 1992-97. Changes in observed characteristics of the unemployed (including duration of unemployment as well as age and education) appear to have relatively little to do with this.

- The probability of active search appears to be similar for those receiving UI and UA in Hungary in 1997, which calls into doubt arguments that the transition from one benefit type to another is associated with a drop in search activity.

\section{ACKNOWLEDGEMENTS}

The research for this paper was financed by EC PHARE-ACE grant P95-2081-R ("State Responses to Poverty and Unemployment in Hungary"). We thank the Hungarian Central Statistical Office, and especially Judit Lakatos, for providing us with labour force survey microdata.

\section{REFERENCES}

Atkinson, A. B. and Micklewright, J. (1991): Unemployment compensation and labor market transitions: a critical review. Journal of Economic Literature, 29: 1679-1727.

Blank, R. and Card, D. (1991): Recent trends in insured and uninsured unemployment; is there an explanation? Quarterly Journal of Economics, November, 1157-1189.

Boeri, T. (1994): 'Transitional' unemployment. Economics of Transition, 2 (1): 1-26. 
Burda, M. (1993): Unemployment, labor markets and structural change in Eastern Europe. Economic Policy, 16: 101-137.

Creedy, J. and Disney, R. (1981): Eligibility for unemployment benefits. Oxford Economic Papers, 33: 256-273.

Gomulka, J. and Stern, N. (1990): The employment of married women in the UK, 1970-83. Economica, 57: 171-199.

Gora, M. and Schmidt, C. (1998): Long term unemployment, unemployment benefits and social assistance: the Polish experience. Empirical Economics, 23 (1/2): 55-86.

Micklewright, J. and Nagy, Gy. (1998): Unemployment assistance in Hungary. Empirical Economics, 23 (1/2): 155-176.

Micklewright, J. and Nagy, Gy. (1999): Living standards and incentives in transition: the implications of exhausting UI in Hungary. Journal of Public Economics, 73 (3): 297-320.

OECD (1994): The OECD Jobs Study: Evidence and Explanations. Paris: OECD.

OECD (1996): Lessons From Labour Market Policies in the Transition Countries. OECD Proceedings, Centre for Co-operation with the Economies in Transition, Paris. 